\title{
COMPARATIVE ANALYSIS OF OPERATIVE TIME, LENGTH OF STAY IN ICU AND ESTIMATED BLOOD LOSS IN ROBOT- ASSISTED AND LAPAROSCOPIC SURGERY
}

\author{
${ }^{1}$ Kameliya Tsvetanova, ${ }^{2}$ Maria Atanasova, ${ }^{3}$ Borislava Ivova, ${ }^{3}$ Latchesar Tanchev \\ ${ }^{1}$ Clinic of Anaesthesiology, Resuscitation and Intensive Care, Oncology Center, \\ University Hospital „Georgi Stranski“- Pleven, Bulgaria \\ ${ }^{2}$ Clinic of Anaesthesiology, Resuscitation and Intensive Care, \\ University Hospital „St. Anna“- Sofia, Bulgaria \\ ${ }^{3}$ Clinic of Gynecologic Oncology, University Hospital „Georgi Stranski“- Pleven, Bulgaria
}

\begin{abstract}
INTRODUCTION: Minimally invasive surgical techniques are increasingly utilized in contemporary surgical practice worldwide. Despite the similarities between them, such as minimal tissue trauma, improved visibility of the operative field, etc., there are also a number of differences. The most common of them are related to the operative time and length of stay in the intensive care unit (ICU), as well as the amount of intraoperative blood loss.
\end{abstract}

AIM: The aim of this study is to compare the length of ICU stay, the need for blood transfusion due to intraoperative bleeding and the mean operative time in accordance with the body mass index among Bulgarian female patients, who have undergone laparoscopic and robot-assisted gynecological surgery.

METHODS: We analyzed 460 women with benign and malignant gynecological diseases who were operated on at the Gynecology Clinic at the University Hospital - Pleven, Bulgaria from 2007 to 2015. Robot-assisted surgery was performed on 223 patients, and laparoscopic surgery - on 247 patients.

RESULTS: We found out that ICU stay (in days) was 1.12 in the group of robot-assisted operations, and 1.05 - in the laparoscopic surgery group. The operative time in laparoscopic operations was significantly shorter, as compared to robot-assisted operations.

CONCLUSION: The need for blood transfusion was determined, considering the estimated intraoperative blood loss and the changes of hemoglobin and hematocrit levels in the postoperative period, compared to their preoperative values. Three prognostic groups were formed.

Keywords: robotic surgery, length of ICU stay, blood transfusion, operative time

Address for correspondence:

Kameliya Tsvetanova

Department of Anaesthesiology, Resuscitation and Intensive

Care, Oncology Center, University Hospital - Pleven

8 a Georgi Kochev Str.

5800 Pleven, Bulgaria

e-mail:kamelia_tsvetanova@abv.bg

Received: December 1, 2015

Accepted: February 17, 2016

\section{INTRODUCTION}

At present, robotic surgery with the Da Vinci system is widely used for the treatment of a number of benign and malignant diseases. Originially developed for the needs of NASA as a telesurgery robotic system for remotely performed surgery on war victims on the battlefield, it is now gaining popularity in different areas of on-site minimally invasive surgery (1). 
Kameliya Tsvetanova, Maria Atanasova, Borislava Ivova et al.

The other most commonly used minimally invasive method is laparoscopic surgery. The two techniques, however, have essential differences. The laparoscopic instruments cause reduced tactile feedback and paradoxical movements. The tremor of the hands is amplified at the distal end, and the effector part of the instruments has limited movements. The monitor reproduces the operative field in two dimensions, which is associated with a change in the "handeye" coordination feedback. In most cases, the surgeon works in insufficiently ergonomic position and environment. Altogether, these circumstances form a hardly surmountable barrier for a beginner in laparoscopic surgery, especially in radical procedures, which in turn is a prerequisite for many obstacles during surgery.

Unlike laparoscopic instruments, the robotic surgical systems overcome many of the disadvantages of classical laparoscopy. The robotic „arms“ have seven degrees of freedom of movement, similar to those of the human hand, and electronic control makes them more precise and eliminates tremor. The human hand is capable of $180^{\circ}$ movements. In comparison, each arm of the Da Vinci robot performs $540^{\circ}$ movements and provides better mobility of the surgeon. The surgeon works comfortably in an ergonomic environment, sitting behind the console and has a three-dimensional view to the field. This implies less tissue trauma, less blood loss in the intraoperative and postoperative period, and a better quality of life after surgery.

\section{AIM}

The aim of this study is to compare the length of ICU stay, the need for blood transfusion due to intraoperative bleeding and the mean operative time in accordance with the body mass index among Bulgarian female patients, who have undergone laparoscopic and robot-assisted gynecological surgery.

\section{MATERIALS AND METHODS}

The study involved 470 women with gynecological diseases (both benign and malignant), operated on in the Clinic of Gynecology at University Hospital - Pleven, Bulgaria for a period of 8 years (20072015). The average age of the patient was $45.35 \pm 8.14$ years, age range 30-69 years. Of all the patients, 223 (47.4\%) underwent robot-assisted operations for ma- lignant diseases, and 247 (52.6\%) underwent laparoscopic operations for benign diseases.

The largest number of patients with robotic operations was from the 40-49-year-old age group (78 patients), followed by the 50-59-year-old group with 65 patients, and the group of 60-69-year-olds (18 patients). In the laparoscopic surgery group, the 40-49-year-old age group included the largest number of patients (126), followed by 30-39-year-olds (63 patients), while the smallest group was of the 60-69-year-olds (5 patients).

\section{Clinical Methods}

The clinical methods used included patient history, physical examination, consultation with an anesthesiologist, intensive care specialist, internist, if necessary, a cardiologist, endocrinologist or other specialists.

\section{Laboratory Methods}

The following laboratory tests were performed preoperatively and on the first two postoperative days: complete blood count, hemostasis tests - activated partial thromboplastin time (aPTT), prothrombin time (PT), fibrinogen, bleeding time, clotting time; blood sugar; serum electrolytes $(\mathrm{Na}+, \mathrm{K}+$, $\mathrm{Ca}+\mathrm{Cl}+$ ), blood gas analysis, total serum protein (total protein, albumin).

\section{Instrumental Methods}

Chest radiographs and ECG were performed.

Operative time was defined as the interval in minutes between the skin incision to the anterior abdominal wall (LH, TAH and RAH) or the incision to the vaginal mucosa (TVH) and the last suture of the abdominal wall skin (LH, TAH and RAH), or the vaginal mucosa $(\mathrm{TVH})$ (skin/mucosa incision time closure time).

Blood transfusion was carried out at a hemoglobin level $<80 \mathrm{~g} / \mathrm{l}$.

\section{Statistical Methods}

The data was processed with the software package for statistical analysis SPSS 13.0. The significance level, rejecting the null hypothesis was set to $\mathrm{p}<0.05$

The following statistical methods were used:

1. Descriptive analysis - the frequency-related distribution of the examined signs, divided into study groups, was presented in a tabular form 
2. Variation analysis - used to assess the characteristics of central tendency and statistical dispersion

\section{RESULTS}

The analysis included only patients with statistically significant diagnoses, namely: uterine fibroids (myoma), ovarian cyst, cervical cancer and endometrial cancer.

The results of our study showed a decrease in the hemoglobin concentration levels in the early postoperative period, compared to the preoperative values in both groups. The hemoglobin level remained stable on the next day in the robot-assisted group, but had a significant decrease in the laparoscopic group. The fact that the average hemoglobin concentration in the laparoscopic group was significantly lower in the preoperative period contributes to the difference between the hemoglobin level changes in the two groups.

Hematocrit in both groups lowered significantly in the early postoperative period and raised sta- tistically significantly on the next day. Still, the level remained significantly lower than the preoperative one. The level of this parameter was significantly higher in the robotic-surgery group at the early postoperative stage (Table 1).

All four groups of patients with statistically significant diagnoses had significantly decreased hemoglobin levels in the early postoperative period. The group with ovarian cyst diagnosis showed statistically significant increase of hemoglobin levels on the day following the surgery, while the level in the other three groups remained the same from a statistical point of view.

Patients in all four groups were found with a significant decrease of hematocrit level in the early postoperative period. The ovarian cyst and cervix cancer patients showed a statistically significant increase of hematocrit levels on the day after the surgery, while patients in the other two groups it remained the same from a statistical point of view (Table 2).

Table 1. Hemoglobin and hematocrit level changes in patients with the two types of surgery

\begin{tabular}{|c|c|c|c|c|c|c|c|}
\hline \multirow{3}{*}{$\begin{array}{l}\text { Type of } \\
\text { surgery }\end{array}$} & \multirow{3}{*}{$\begin{array}{l}\text { Number } \\
\text { of cases }\end{array}$} & \multicolumn{3}{|c|}{$\mathbf{H b}$} & \multicolumn{3}{|c|}{ Hct } \\
\hline & & $\begin{array}{c}\text { Preoperative } \\
\text { period }\end{array}$ & $\begin{array}{l}\text { Early postop- } \\
\text { erative period }\end{array}$ & The next day & $\begin{array}{c}\text { Preoperative } \\
\text { period }\end{array}$ & $\begin{array}{l}\text { Early postop- } \\
\text { erative period }\end{array}$ & The next day \\
\hline & & $\overline{\mathrm{X}}$ & $\bar{X}$ & $\bar{X}$ & $\bar{X}$ & $\overline{\mathrm{X}}$ & $\bar{X}$ \\
\hline $\begin{array}{l}\text { Robot- } \\
\text { assisted }\end{array}$ & 223 & $127.48^{\mathrm{a}} \pm 12.54$ & $112.22^{b} \pm 13.45$ & $112.57^{b} \pm 12.42$ & $0.363^{a} \pm 0.039$ & $0.321^{\mathrm{b}} \pm 0.040$ & $0.324^{c} \pm 0.038$ \\
\hline $\begin{array}{l}\text { Laparo- } \\
\text { scopic }\end{array}$ & 247 & $124.00^{\mathrm{a}} \pm 12.37$ & $109.76^{\mathrm{b}} \pm 12.34$ & $111.27^{\mathrm{c}} \pm 12.50$ & $0.358^{a} \pm 0.039$ & $0.314^{\mathrm{b}} \pm 0.042$ & $0.318^{c} \pm 0.042$ \\
\hline $\mathrm{p}$ & & 0.003 & 0.063 & 0.330 & 0.109 & 0.025 & 0.122 \\
\hline
\end{tabular}

Table 2. Hemoglobin and hematocrit level changes in the different groups of diagnoses

\begin{tabular}{|c|c|c|c|c|c|c|c|}
\hline \multirow{3}{*}{ Diagnosis } & \multirow{3}{*}{$\begin{array}{l}\text { Number } \\
\text { of cases }\end{array}$} & \multicolumn{3}{|c|}{$\mathbf{H b}$} & \multicolumn{3}{|c|}{ Hct } \\
\hline & & $\begin{array}{c}\text { Preoperative } \\
\text { period }\end{array}$ & $\begin{array}{l}\text { Early postop- } \\
\text { erative period }\end{array}$ & The next day & $\begin{array}{c}\text { Preoperative } \\
\text { period }\end{array}$ & $\begin{array}{l}\text { Early postop- } \\
\text { erative period }\end{array}$ & The next day \\
\hline & & $\overline{\mathrm{X}}$ & $\bar{X}$ & $\bar{X}$ & $\overline{\mathrm{X}}$ & $\overline{\mathrm{X}}$ & $\overline{\mathrm{X}}$ \\
\hline Myoma & 154 & $124,21^{\mathrm{a}} \pm 12.60$ & $109,1^{\mathrm{b}} \pm 13.28$ & $110,35^{\mathrm{b}} \pm 13.51$ & $0,362^{\mathrm{a}} \pm 0.039$ & $0,314^{\mathrm{b}} \pm 0.045$ & $0,317^{\mathrm{b}} \pm 0.046$ \\
\hline $\begin{array}{l}\text { Ovarian } \\
\text { cyst }\end{array}$ & 93 & $123,66^{a} \pm 12.05$ & $110,77^{\mathrm{b}} \pm 10.57$ & $112,78^{c} \pm 10.50$ & $0,352^{\mathrm{a}} \pm 0.037$ & $0,313^{\mathrm{b}} \pm 0.037$ & $0,320^{c} \pm 0.035$ \\
\hline $\begin{array}{l}\text { Cervical } \\
\text { cancer }\end{array}$ & 155 & $126,68^{a} \pm 11.87$ & $111,1^{\mathrm{b}} \pm 13.09$ & $111,97^{\mathrm{b}} \pm 12.22$ & $0,361^{\mathrm{a}} \pm 0.038$ & $0,317^{\mathrm{b}} \pm 0.038$ & $0,322^{c} \pm 0.037$ \\
\hline $\begin{array}{l}\text { Endometrial } \\
\text { cancer }\end{array}$ & 58 & $130,66^{\mathrm{a}} \pm 12.69$ & $115,9^{\mathrm{b}} \pm 12.30$ & $114,97^{\mathrm{b}} \pm 11.79$ & $0,371^{\mathrm{a}} \pm 0.042$ & $0,333^{\mathrm{b}} \pm 0.044$ & $0,331^{\mathrm{b}} \pm 0.039$ \\
\hline
\end{tabular}


Kameliya Tsvetanova, Maria Atanasova, Borislava Ivova et al.

The only significant difference between the four groups was observed in the hemoglobin levels on the next day after the surgery, compared to preoperative levels. The average value of this change of hemoglobin levels was significantly lower in patients with ovarian cysts, as compared with the other groups.

Significant difference between the four groups was observed in the dynamics of hematocrit in the early postoperative period, compared to preoperative levels and on the day following the surgery, as compared to the preoperative period. The average value of this change was significantly lower in patients with ovarian cancer, as compared to those with uterine fibroids and cervix cancer (Table 3).

Based on these results, an analysis of the correlation between the diagnoses and the need for blood
Group No.2 - in cases with uterine fibroids, the probability of occurrence of need for transfusion is 1.3/1 compared to that in cases of no occurrence.

Group No.3 - in cases with cervix cancer the probability of occurrence of the need for transfusion is $1.7 / 1$ compared to that in cases of no occurrence.

Comparison of the parameters: length of stay in the ICU in patients with different diagnoses found no significant difference between them (Table 5).

Analysis of the parameters: operative time and BMI, showed that BMI correlates poorly and proportionally to the operative time only in patients, diagnosed with an ovarian cyst (Table 6).

\section{DISCUSSION}

Hematocrit is a laboratory parameter for the ra-

Table 3. Comparative analysis of the operations (the diagnoses groups), considering hemoglobin and hematocrit level

\begin{tabular}{|c|c|c|c|c|c|c|c|}
\hline \multirow{3}{*}{ Diagnosis } & \multirow{3}{*}{$\begin{array}{l}\text { Number } \\
\text { of cases }\end{array}$} & \multicolumn{3}{|c|}{$\mathrm{Hb}$} & \multicolumn{3}{|c|}{ Hct } \\
\hline & & $\begin{array}{c}\text { Ratio: } \\
\text { Preoperative } \\
\text { to early } \\
\text { postoperative }\end{array}$ & $\begin{array}{l}\text { Ratio: } \\
\text { Preoperative } \\
\text { to level on } \\
\text { the next day }\end{array}$ & $\begin{array}{c}\text { Ratio: } \\
\text { On the next } \\
\text { day to early } \\
\text { postoperative }\end{array}$ & $\begin{array}{c}\text { Ratio: } \\
\text { Preoperative } \\
\text { to early } \\
\text { postoperative }\end{array}$ & $\begin{array}{c}\text { Ratio: } \\
\text { Preoperative } \\
\text { to level on } \\
\text { the next day }\end{array}$ & $\begin{array}{c}\text { Ratio: } \\
\text { On the next } \\
\text { day to early } \\
\text { postoperative }\end{array}$ \\
\hline & & $\overline{\mathrm{x}}$ & $\overline{\mathrm{X}}$ & $\overline{\mathrm{X}}$ & $\overline{\mathrm{X}}$ & $\overline{\mathrm{X}}$ & $\overline{\mathrm{X}}$ \\
\hline Myoma & 154 & $15.06^{\mathrm{a}} \pm 10.47$ & $13.86^{\mathrm{a}} \pm 10.60$ & $1.20^{\mathrm{a}} \pm 9.15$ & $0.049^{\mathrm{a}} \pm 0.042$ & $0.046^{\mathrm{a}} \pm 0.049$ & $0.003^{\mathrm{a}} \pm 0.049$ \\
\hline Ovarian cyst & 93 & $12.88^{\mathrm{a}} \pm 8.55$ & $10.87^{\mathrm{b}} \pm 8.49$ & $2.01^{\mathrm{a}} \pm 6.84$ & $0.038^{\mathrm{bc}} \pm 0.039$ & $0.031^{\mathrm{bc}} \pm 0.040$ & $0.007^{\mathrm{a}} \pm 0.028$ \\
\hline $\begin{array}{l}\text { Cervix } \\
\text { cancer }\end{array}$ & 155 & $15.59^{\mathrm{a}} \pm 10.29$ & $14.72^{\mathrm{a}} \pm 9.77$ & $0.87^{\mathrm{a}} \pm 10.76$ & $0.044^{\mathrm{a}} \pm 0.036$ & $0.039^{\mathrm{a}} \pm 0.035$ & $0.005^{\mathrm{a}} \pm 0.033$ \\
\hline $\begin{array}{l}\text { Endometrial } \\
\text { cancer }\end{array}$ & 58 & $14.74^{\mathrm{a}} \pm 10.53$ & $15.69^{\mathrm{a}} \pm 11.28$ & $-0.95^{\mathrm{a}} \pm 8.44$ & $0.038^{\mathrm{ac}} \pm 0.041$ & $0.040^{\mathrm{ac}} \pm 0.042$ & $-0.002^{\mathrm{a}} \pm 0.037$ \\
\hline
\end{tabular}

transfusion was made. The number of patients with the diagnoses of ovarian cyst, endometrial cancer and hyperplasia and polyp of the endometrium who did not need blood transfusion were significantly larger. Those with cervix cancer, on the other hand, needed blood transfusion.

Considering the data from Table 4, three prognostic groups of patients who needed blood transfusion can be formed:

Group No.1 - in cases with diagnoses of ovarian cyst, endometrial cancer, hyperplasia and polyp of the endometrium, it is about $100 \%$ likely that a transfusion of blood will not be necessary. tio of the volume of red blood cells to the total volume of blood. It is a relative indicator, used to evaluate acute and chronic blood loss as well as changes in the fluid-electrolyte balance. In mammals, the hematocrit is independent of body size. This is why we use this parameter along with the postoperative hemoglobin concentration for an indirect assessment of intraoperative blood loss.

The majority of authors evaluate intraoperative blood loss as the amount of blood that the patient has lost in milliliters (Jelovsek et al., 2007; Mahdavi et al., 2006; O’Hanlan et al., 2004; Twignstra et al., 2009). As this is an absolute value, it does not adequately re- 
Comparative Analysis of Operative Time, Length of Stay in ICU and Estimated Blood Loss in Robot-Assisted and ...

Table 4. Analysis of the correlation between the diagnosis and the need for blood transfusion

\begin{tabular}{|c|c|c|c|c|}
\hline \multirow{2}{*}{ Diagnosis } & \multirow{2}{*}{ Frequency } & \multicolumn{2}{|c|}{ Need for blood transfusion } & \multirow{2}{*}{$\mathrm{P}$} \\
\hline & & NO & YES & \\
\hline \multirow{2}{*}{ Uterine fibroids (Myoma) } & Number & 145 & 9 & \\
\hline & $\%$ & 32.4 & 40.9 & n.s. \\
\hline \multirow{2}{*}{ Ovarian cyst } & Number & 93 & 0 & \\
\hline & $\%$ & 20.8 & 0 & $<0.001$ \\
\hline \multirow{2}{*}{ Cervical cancer } & Number & 143 & 12 & \\
\hline & $\%$ & 31.9 & 54.5 & $<0.05$ \\
\hline \multirow{2}{*}{ Endometrial cancer } & Number & 58 & 0 & \\
\hline & $\%$ & 12.9 & 0 & $<0.001$ \\
\hline \multirow{2}{*}{ Ovarian cancer } & Number & 3 & 0 & \\
\hline & $\%$ & 0.7 & 0 & n.s. \\
\hline \multirow{2}{*}{ Hyperplasia and polyp of the endometrium } & Number & 6 & 0 & \\
\hline & $\%$ & 1.3 & 0 & $<0.05$ \\
\hline \multirow{2}{*}{ Uterine sarcoma } & Number & 0 & 1 & \\
\hline & $\%$ & 0 & 4.5 & n.s. \\
\hline \multirow{2}{*}{ Total } & Number & 448 & 22 & \\
\hline & $\%$ & 100.0 & 100.0 & \\
\hline
\end{tabular}

Table 5. Comparison of length of stay in the ICU of patients with different diagnoses

\begin{tabular}{|c|c|c|c|}
\hline Diagnosis & n & $\bar{X}_{\text {(days) }}$ & SD \\
\hline Uterine fibroids (Myoma) & 154 & $1.08^{\mathrm{a}}$ & 0.33 \\
\hline Ovarian cyst & 93 & $1.01^{\mathrm{a}}$ & 0.10 \\
\hline Cervical cancer & 155 & $1.14^{\mathrm{a}}$ & 0.61 \\
\hline Endometrial cancer & 58 & $1.05^{\mathrm{a}}$ & 0.29 \\
\hline Ovarian cancer & 3 & 1.00 & 0.00 \\
\hline Hyperplasia and polyp of the endometrium & 6 & 1.00 & 0.00 \\
\hline 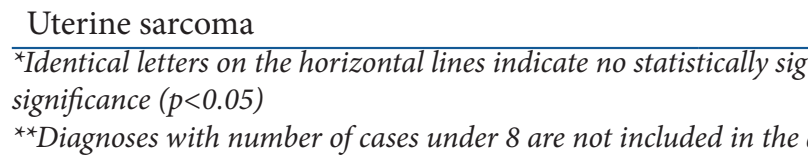 & 1 & $\begin{array}{l}2.00 \\
\text { tetters } \\
\text { tatistical }\end{array}$ & ce of such \\
\hline $\begin{array}{l}\text { flect the clinical importance which losing a certain } \\
\text { amount of blood can have on the patient }(2,3,4,5) \text {. } \\
\text { The results of our study revealed that the need } \\
\text { for blood transfusion was most common in patients, } \\
\text { diagnosed with uterine fibroids who have undergone } \\
\text { conventional laparoscopic surgery and in patients } \\
\text { with cervix cancer who have undergone robot-assist- } \\
\text { ed surgery. }\end{array}$ & \multicolumn{3}{|c|}{$\begin{array}{l}\text { In a study by Payne et al (2008.), robot-assisted } \\
\text { operations were an average } 27 \mathrm{~min} \text {. longer than lap- } \\
\text { aroscopic ones. The authors noted, however, that the } \\
\text { last } 25 \text { out of } 100 \text { robot-assisted cases were performed } \\
\text { faster than the average time for laparoscopic opera- } \\
\text { tions ( } 92.4 \mathrm{~min} \text { compared to } 78.7 \mathrm{~min}) \text {. They also re- } \\
\text { ported a difference of about } 52 \mathrm{ml} \text { in the blood loss } \\
\text { between robotic and laparoscopic surgery in favor of } \\
\text { the robot-assisted hysterectomies }(6) \text {. }\end{array}$} \\
\hline
\end{tabular}


Kameliya Tsvetanova, Maria Atanasova, Borislava Ivova et al.

Table 6. Analysis of the correlation between BMI and operative time in the different groups, based on the diagnosis

\begin{tabular}{lc|c} 
Diagnosis & Parameters & Operative time \\
Uterine fibroids & & -0.091 \\
Ovarian cyst & BMI & $0.241^{*}$ \\
Cervical cancer & & -0.124 \\
Endometrial cancer & & 0.047 \\
\hline${ }^{*} p<0.05$
\end{tabular}

Other studies, also reporting longer operative time in robot-assisted operations are those of Shashoua al (2009) and Nezhat et al. (2009). According to them, operative time was increased to $20 \mathrm{~min}$ and to 70 min, respectively $(7,8)$.

The research of Seamon et al. (2009) and Boggess et al. (2008), on the other hand, determined a shorter operative time for the robotic surgery group compared to the laparoscopic surgery group of about $45 \mathrm{~min}$. in the first study and $22 \mathrm{~min}$. in the second one $(9,10)$.

Enrique Soto et al (2011) compared 124 patients, undergoing laparoscopic and robotic hysterectomies: 77 laparoscopic and 47 robotic surgery cases. In the laparoscopic group there were significantly more patients with estimated blood loss greater than 200 $\mathrm{mL}$ compared to the robotic group and this difference proved to be statistically significant ( $\mathrm{p}=0.009$ ). The estimated blood loss in the laparoscopic surgery group was $207.7 \mathrm{~mL}$ and $131.50 \mathrm{~mL}$ in the robotic surgery group. This difference turned out to be statistically significant $(\mathrm{p}=0.0105)$ although the $76 \mathrm{~mL}$ difference in the groups had no obvious clinical significance and need for blood transfusion (11).

These studies partially support our own results. We associate more frequent transfusions in the group of uterine fibroid diagnosis with chronic blood loss and the development of anemia syndrome in these patients. In the cervical cancer group the need for blood transfusion is associated with the greater volume of surgery.

The same authors demonstrated that the two groups of patients had comparable length of hospital stay - 2.2 days for the laparoscopic surgery group and 1.9 for the robotic surgery one. This again is in support of our results.

Tomov et al. (2012) presented interesting data in their study of body mass index and operative time. The regression analysis they conducted indicated a significant correlation between the two parameters. Increasing BMI with $1 \mathrm{~kg} / \mathrm{m} 2$ resulted in an average 0.6 minutes increase in the operative time $(\mathrm{p}=0.026)$. In our research, we found such dependence only in patients, diagnosed with ovarian cysts.

\section{CONCLUSIONS}

High technologies in medicine are being increasingly utilized in the surgical practice worldwide. Their main aim is to achieve greater precision, to reduce pain and complications and to improve the quality of life in the postoperative period. The conventional laparoscopic and the robot-assisted surgical techniques are closest to achieving these goals.

Less tissue trauma and small amount of blood loss are a prerequisite for a short stay in the intensive care unit, higher quality of life in the early postoperative period and a rapid return of the patients to their social activities.

\section{REFERENCES}

1. Advincula A.R. Surgical techniques: robot-assisted laparoscopic hysterectomy with the da Vinci surgical system. Int J Med Robot.2006;2:305-311.

2. Jelovsek, J. E., C. Chiung, G. Chen, S. L. Roberts, M. F. R. Paraiso, T. Falcone. Incidence of lower urinary tract injury at the time of total laparoscopic hysterectomy. J Soc Laparoendosc Surg., 2007, 11: 422-427.

3. Mahdavi, A., M. Peiretti, S. Dennis, F. Nezhat. Comparison of Laparoscopic Hysterectomy Morbidity for Gynecologic, Oncologic, and Benign Gynecologic Condions. Journal of the Society of Laparoendoscopic Surgeons (JSLS), 2006, 10: 439-442.

4. O'Hanlan, K., G. S. Huang, L. Lopez, A. Garnier. Total laparoscopic hysterectomy for oncological indications with outcomes stratified by age. Gynecologic Oncology, 2004, 95: 196-203.

5. Twinsrta, A. R. H., N. A. Kianmanesh Rad, M. J. G. H. Smeets, J.F. Admiraal, F. W. Jansen. Twenty-first 
century laparoscopic hysterectomy: schoud we not leave the vaginal step out? Gynecol Surg 2009; DOI 10.1007/s10397-009-0481-7.

6. Payne T.N., Dautrevie F.R. A comparison of total laparoscopic hysterectomy to robotcally assisted hysterectomy:surgical ourcomes in a community practice. J Minim Invasive Gynec. 2008;15:286-291.

7. Shashoa A.R., Gill D., Locher S.R. Robotic-assisted total laparoscopic hysterectomy versus conventional total laparoscopic hysterectomy. JSLS.2009;13:364-369.

8. Nezhat C., Lavie O., Lemyre M., Gemer O., Bhagan L., Neezhat C. Laparoscopic hysterectomy with and without a robot: Stanford experience. JSLS. 2009;13:125-128.

9. Seamon L.G., Cohn D.E., Henretta M.S., Kim K.H., Carlson M.J., Phillips G.S. et.al. Minimally invasive comprehensive surgical for endometrial cancer:Robotic or laparoscopy? Gynecol Oncol. 2009; 113:36-41.

10. Bogges J.F., Gehring P.A., Cantrell L., Shafer A., Ridway M., Skinner E.N. et al. A comparative study of 3 surgycal methods for hysterectomy with staging for endometrial cancer: robotic assistance, laparoscopy, laparotomy. Am J Obstet Gynecol. 2008;199:360.el-360.e9.

11. Soto E, Lo Y, Friedman K, Soto C et al. Total laparoscopic hysterectomy versus da Vinci robotic hysterectomy: is using the robot beneficial?

12. Tomov Sl. Clinical significance and the place of laparoscopic hysterectomy in the contemporary gynecology surgery. Dissertation. Pleven, 2012 